Article

\title{
Visual Arts in the University Educational Ecosystem: Analysis of Schools of Knowledge
}

\author{
Mariana-Daniela González-Zamar ${ }^{1, *(D)}$ and Emilio Abad-Segura ${ }^{2}$ (D) \\ 1 Department of Education, University of Almeria, 04120 Almeria, Spain \\ 2 Department of Economics and Business, University of Almeria, 04120 Almeria, Spain; eas297@ual.es \\ * Correspondence: mgz857@ual.es
}

Citation: González-Zamar, M.-D.; Abad-Segura, E. Visual Arts in the University Educational Ecosystem: Analysis of Schools of Knowledge. Educ. Sci. 2021, 11, 184. https:// doi.org/10.3390/educsci11040184

Academic Editor: James Albright

Received: 11 March 2021

Accepted: 13 April 2021

Published: 14 April 2021

Publisher's Note: MDPI stays neutral with regard to jurisdictional claims in published maps and institutional affiliations.

Copyright: (c) 2021 by the authors. Licensee MDPI, Basel, Switzerland. This article is an open access article distributed under the terms and conditions of the Creative Commons Attribution (CC BY) license (https:// creativecommons.org/licenses/by/ $4.0 /)$.

\begin{abstract}
Throughout history, the visual arts have allowed for a dynamic of aesthetic feedback, cultural plurality, and a standardization of the artistic phenomenon. The objective of this study is to analyze the current lines of research at the international level, during the period 1952-2020, on the visual arts in the university educational ecosystem. Bibliometric techniques were applied to 1727 articles in the thematic area of the "Arts and Humanities" to obtain the findings included in this report. Scientific production has increased mainly in the last decade, making up around 70\% of all publications. Five schools of knowledge have been identified that generate articles on this topic related to art, visual culture, modernity, music, and history. The growing trend of scientific production worldwide shows the interest in developing aspects of this field of study. This article contributes to the academic, scientific, and institutional discussion on the role of the visual arts in contemporary society.
\end{abstract}

Keywords: visual art; creative; plastic art; university ecosystem; scientific production

\section{Introduction}

As a creative discipline, visual art encompasses traditional plastic arts, as well as expressions that incorporate new art-oriented technologies or unconventional elements [1,2]. Its main expressive component is visual, as occurs in the disciplines of photography, painting, videography, cinematography, and new media art, among which photography, digital art, fan art, net.art, or video art stand out [3-5].

The first artistic manifestations of the human being belong to prehistoric times, during the Paleolithic era more than 30,000 years ago, when they decorated the interior of the caves inhabited with mixtures of pigments and animal fats [6]. These first human creations were determined by religious motivations linked to magic and rituals or narrative purposes, not being considered works with an aesthetic or ornamental purpose.

Hence, the concept of art did not always exist, but arose in classical antiquity, when art was given a formal, technical, structural, and ideological interpretation [7]. Over time, art (from the Latin ars, artis, and this from the Greek $\tau \dot{\varepsilon} \chi \vee \eta$ téchnē) has been understood as any activity or product carried out with an aesthetic and communicative purpose, through which ideas and emotions are expressed through various resources, such as plastic, linguistic, sound, bodily, and mixed forms [8,9]. Art is a component of culture, reflecting in its conception the economic and social bases, and the transmission of ideas and values, that are inherent to any human culture throughout space and time [10].

In classical culture, the concept of beauty was related to the defense and use of symmetry, mathematical calculations, and proportion. In successive historical periods, different parameters have been applied to beauty, aware that it is a quality present in the mind of human beings that produces intense pleasure and comes from sensory or ideal manifestations [11]. The concept of beauty was accentuated after the artistic and philosophical outbreak of the European Renaissance. Likewise, the conception of beauty was based on a harmony of proportions, where artists strove to find the most perfect canons 
of beauty, therefore introducing man as a being made on the basis of proportions [12,13]. In the Baroque period, the geometric and defined forms of the Renaissance were avoided, and a clear trend towards the emotional was adopted, leaving a the rational aside [14]. The 21st century arrived with new airs, breaking with the ideal of beauty and the classic canons, and constructing or deconstructing nature from its own vision of the world $[15,16]$.

In the 18th century the concept of the fine arts emerged, and it was during the 19th and 20th centuries, from the great diversification and liberalization of the arts, when the fine arts were considered as the set of artistic manifestations of a creative nature with aesthetic value [17]. Similarly, other expressions of art appeared in the 20th century, such as environmental, kinetic, ephemeral, urban, or land art [18,19].

Art is one of the most important and lasting manifestations of the human, which allows us to reflect on who we are as a species. In this context, art has developed from different disciplines such as literature, theater, music, or painting. Thanks to the use of technologies, art has been reflected and enriched, especially in photography, cinema, or digital art, as a creative discipline that includes works in which digital elements are used in the production or exhibition process $[16,20]$.

The plastic arts refer to those that use materials that the artist can modify, alter, or combine to produce a work. Traditionally, painting, drawing, sculpture, engraving, ceramics, and goldsmithing have been considered the plastic arts. Subsequently, this term has been deprecated in favor of a broader one: the visual arts. The concept of visual art emerged after World War II, by uniting the arts with visual perception. The composition of the plastic arts developed according to various issues, such as the relationship between figure and background, how to influence perception, and the contour and grouping of elements by proximity, continuity, or similarity [21,22].

The visual arts refer to artistic and expressive representation, whose visual appreciation is based on the artist who creates and remakes fantastic or natural worlds through materials used with different and varied techniques that allow the artist to express their emotions, feelings, and appreciation of the world [23-25]. In general, the visual arts are focused on the vision of nature, as happens in disciplines such as painting, architecture, photography, sculpture, video, or audiovisual production. Likewise, visual arts are characterized by appropriation, that is, by taking elements or styles, either their own or from other currents or movements, and incorporating them into their compositions in an original way [26]. This set of artistic manifestations of a visual nature moves between extrinsic disciplines, but uses them for aesthetic purposes, combining different supports and subjects.

The visual artist is nourished by the phenomenon of globalization, since it facilitates access to artistic proposals that are developed around the world, promoting a dynamic of aesthetic feedback and cultural plurality, in addition to a standardization in the artistic phenomenon [27]. Using different exhibition strategies, the artist seeks to enhance the nature of the works, such as the appropriation of public spaces, the use of the Internet to present the exhibition or the variation of the exhibition periods [28]. For this cause, the visual artist obtains inspiration and creativity from the environment and artistic currents, among which the following stand out: Impressionism, Art Nouveau, Cubism, Futurism, Constructivism, Bauhaus, Art Deco, Surrealism, Abstract Expressionism, Pop Art, Minimalism, Postmodernism and Memphis [26,29].

The schools of knowledge refer to those lines of research that have an approach that encompasses knowledge, concerns, practices, and perspectives of analysis of a particular subject of study, evidencing the future development of research in that field and revealing the possibilities for future development of research in this field [30,31]. Generally, they include a set of projects on the same field, reality, area, or discipline of knowledge, in such a way that their consolidation allows for the generation of currents of thought, and that their results enrich the construction of new knowledge about the realities of societies. The strengthening of lines of research implies the creation of nuclei or groups of researchers that 
with their actions contribute to the formation of critical masses that ensure the continuity of the investigative processes [30,32,33].

The motivation of this study is to document the evolution of schools of knowledge in global research on visual arts in the university educational ecosystem, to detect the thematic axes worked on, and to identify new directions. In the reviewed literature, numerous studies have been identified that address this topic, so the research questions of this study refer to determining the following:

(i) What has been the distribution of scientific production?

(ii) What are the main schools of knowledge?

(iii) What are the future research directions that this topic addresses?

Accordingly, the objective of this study is to analyze schools of knowledge in global research on visual arts in the university educational ecosystem, from 1952 to 2020, that is, from the first article published until the last full year. It is essential to know the state of scientific activity in the field of knowledge to continue with the most appropriate lines of research.

Consequently, the rest of the structure of this study is as follows: Section 2 details the methodology applied; Section 3 consists of the empirical findings and their discussion in a broad context; and the conclusion is presented in Section 4.

\section{Data and Method}

\subsection{Method and Data Collection}

Bibliometrics applies mathematical and statistical methods to literature to analyze the activity of a scientific field. This methodology was initiated by Eugene Garfield in the mid20th century, becoming generalized in the analysis of scientific research and contributing to reviewing knowledge in numerous disciplines. Its explicit objective is to search, identify, and analyze trends in a research topic [34]. Studies on the scientific literature identify relationships between documents in a research area and, therefore, trace their historical development and progress, in addition to recognizing subdisciplines.

Currently, the advantages of bibliographic databases are undeniable since they provide quality and validity to the analysis. Various studies have evaluated which database is the most appropriate to use in bibliometric studies [35-37]. Two scientific databases, Web of Science (WoS) and Scopus, continue to pose the question about the comparison and stability of the statistics obtained. The previous evaluations between the two have not determined which is the best, because everything depends on the focus of the analysis, the discipline, and the time horizon of the study. In this study, both databases were evaluated, because the volume of documents in WoS (Core Collection) was 1517, while in Scopus it was 1727 for the same coverage range.

Figure 1 shows the process for the inclusion and exclusion of records from the sample, according to the Preferred Reporting Items for Systematic Reviews and Meta-Analyses (PRISMA) [38]. The process was as follows:

- Identification: detected 359,900 records from the Scopus database, considering each of the key search terms (visual and art) and "all fields", "all type of documents", and "all the data published in the data range (all years-March 2021).

- Screening: the option "article title, abstract, and keywords" was chosen in the field of each search term, so that 317,158 records were excluded.

- Eligibility: of the 42,742 records, only "articles" were selected as the type of document to ensure the quality derived from the peer review process. In addition, the search was restricted from the origin to the last full year (2020). In this phase, 21,780 records were excluded.

- Included: It this phase the search was limited to the thematic area "Arts and Humanities". Then, 19,235 of the 20,962 records were excluded, so the final sample included 1727 articles (open and non-open access). 


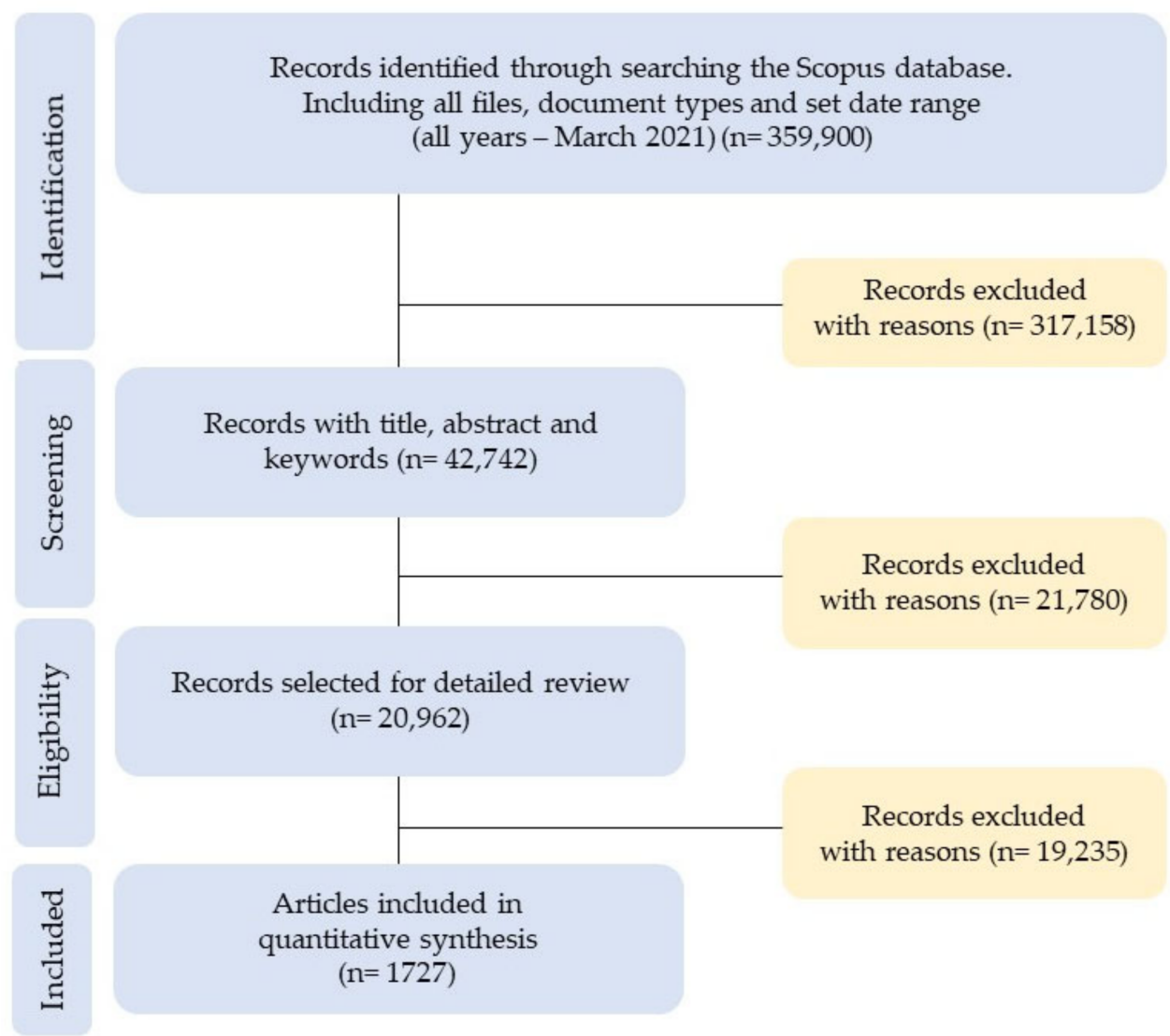

Figure 1. Selected articles based on Preferred Reporting Items for Systematic Reviews and MetaAnalyses (PRISMA).

Hence, the method used consisted of conducting a complete search in Elsevier's Scopus database, using a search string with the terms that make up this research "art" and "visual"). The subfields of the title, abstract, and keywords were examined in the period containing the publication of the first article on the research topic (1952) until the last full year (2020), from the thematic area of "Arts and Humanities", as described in previous bibliometric studies [27,39]. The sample contained 1727 articles. The representation of the sample is supported by the verified quality of the Scopus database, in the indexing protocol, the systematic procedures of the search criteria, and the peer review.

\subsection{Data Processing}

In this study, quantity indicators were analyzed, which refer to productivity, and relationship or structural indicators were analyzed to measure the connections between the keywords that define the documents.

The analysis of the keywords allowed for the detection of the main current and future research topics, based on the co-occurrence method, since scientific texts can be reduced to the set of joint appearances between the terms that compose them. The co-occurrence method refers to the proximity relationship of two or more terms in a text unit; so, if two terms coexist in a sentence (appear together in it), they are likely semantically related. The network based on the co-occurrence method provides a graphic display of the relationships of the concepts represented in the selected articles. The co-occurrence method enables grouping related concepts from the set of articles. In a research topic, relevant terms can be deduced from this method and schools of thought can be extracted [40,41].

The analysis of these relationship indicators was applied with VOSviewer (version 1.6.16, Center for Science and Technology Studies, Leiden University, Leiden, The Netherlands) [42]. This tool provides data on collaborations and evaluation of the contents of the 
sample of selected articles to determine the research activities in networks. In addition, this tool allows you to recognize research trends on the basis of the use of keywords in research articles [43,44].

\subsection{Research Limitations}

The research methodology applied in this study has some limitations; on the other hand, these could become the basis for future research. These limitations refer to the following: (i) bibliometric analysis is mainly a method of quantitative analysis, so the study could be expanded with other quantitative or qualitative tools, in order to seek a different perspective of this research; (ii) some authors publish relatively few scientific documents, but they have great influence on their area of knowledge and impact in a specific field; (iii) this study focused only on articles published in scientific journals, so, in future research, different documents (conference communications, book chapters, books, etc.) should also be included to analyze the impact that they have on the results; and (iv) in future studies the sample could be increased with records from other databases, such as Web of Science or Google Scholar.

\section{Results and Discussion}

\subsection{Scientific Production Analysis}

Figure 2 shows the evolution of scientific production at the international level in the field of visual arts research, in the period 1952-2020. Of the 1727 articles, 669 were published in the last 5 years (2016-2020), that is, $38.74 \%$ of the sample, while in the last decade (2011-2020), 1173 articles (67.92\%) were published. These numbers, with a growing publication, confirm the interest in the topic of research on the visual arts in recent years by the scientific and academic community at a global level.

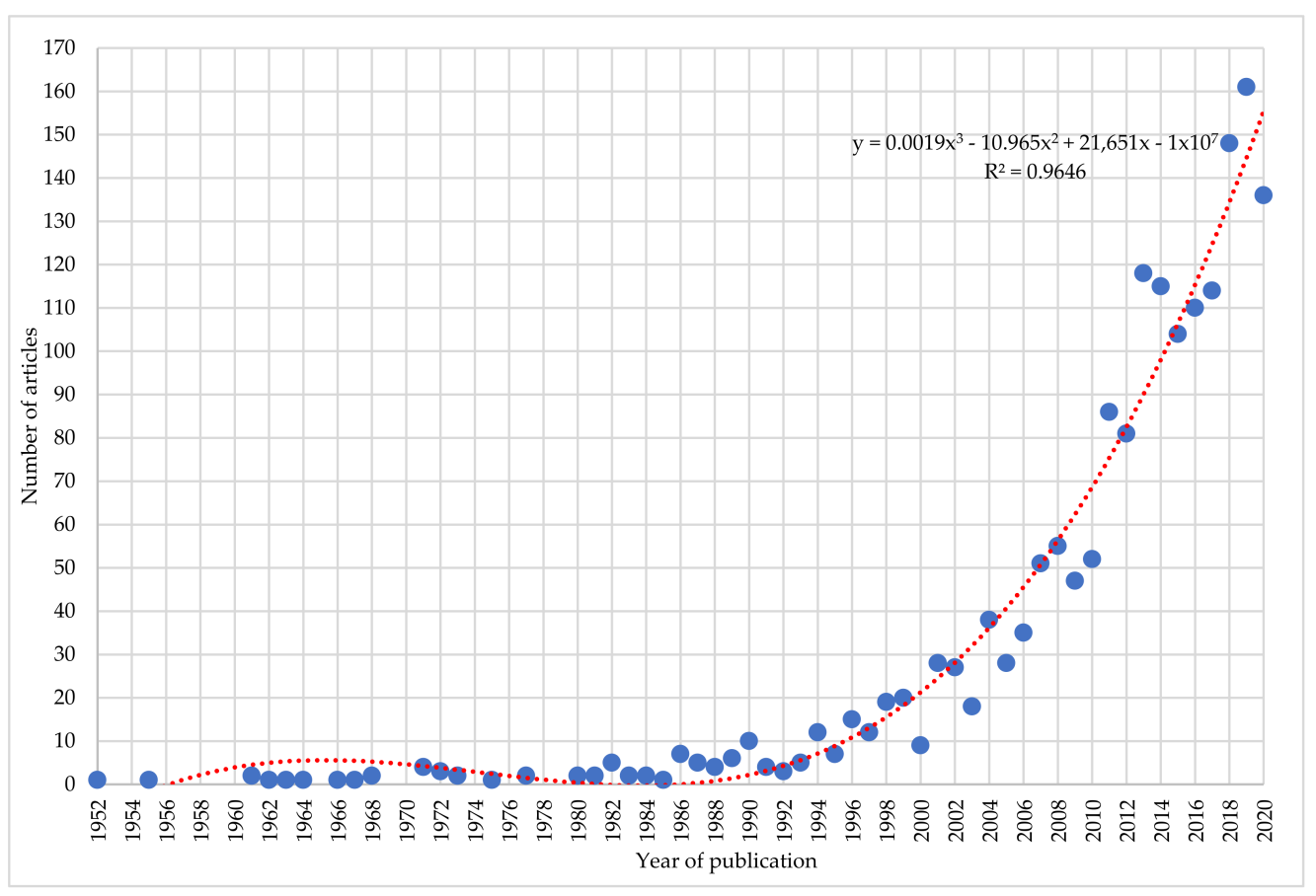

Figure 2. Evolution of scientific production on visual arts in the university educational ecosystem (1952-2020).

An important growth in research activity was observed from 2000 of an advancing in the development of guidelines to improve the quality of arts education at all levels. The emerging challenges of society require exploring new paths for education. In 2006, the UNESCO Chair proposed a roadmap that contemplates the possible contribution of arts 
education to meet the needs for creativity and cultural awareness in the 21st century. This focuses on the strategies necessary to introduce or promote arts education in the learning environment $[7,45]$.

The polynomial trend line of order $3\left(y=0.0019 x^{3}-10.965 x^{2}+21,651 x-1 x 10^{7}\right)$ illustrates the growing relationship between the number of articles published on the visual arts during the period analyzed. The curve shows its goodness with a coefficient of determination $\left(R^{2}\right)$ of 0.9646 , referring to the proportion of the variance in the dependent variable (number of articles published) that is predictable from the independent variable (year of publication), and that represents a good fit of the line to the data set.

The first article on visual arts dates from 1952, entitled "The visual arts in the younger churches", published in the journal International Review of Mission (subject area: Arts and Humanities: Religious Studies) by author Butler, John F. [46].

The most cited article on visual arts, with 67 citations in February 2021, dates from 2010, with the title "The assessment of art attributes", published in the journal Empirical Studies of the Arts (subject area: Arts and Humanities: Literature and Literary Theory, Visual Arts and Performing Arts, and Music), by the authors Chatterjee, A., Widick, P., Sternschein, R., Smith, W., and Bromberger, B. [23]

The most relevant article, that is, the one that most closely matches the search terms in the Scopus database, was cited 6 times, from its publication in 2017 to February 2021. It was published in the journal Arte, Individuo y Sociedad (subject area: Arts and Humanities: Visual Arts and Performing Arts), with the title "Study on the theoretical and methodological approaches of Visual Studies", and written by the Spanish author Contreras-Medina, F.R. [47].

\subsection{Keyword Analysis: Identification of Schools of Knowledge}

In the 1727 articles in the study sample, 4897 different keywords were detected. The analysis of the keywords with the most frequency and relevance provided the identification of a set of research topics, which suggest the most prominent lines of interest among academics during the 1952-2020 period. The 10 most prominent terms in the analyzed sample were art (in 88 articles), visual art (35), photography (33), visual culture (25), history (24), painting (24), contemporary art (22), iconography (22), ekphrasis (20), and aesthetics (19).

Table 1 shows the five clusters detected, the percentage of keywords that they contain over the total, the main keyword that gives the cluster its name, and the 10 most used keywords, ordered by the number of occurrences.

Table 1. Clusters of keywords (1952-2020).

\begin{tabular}{|c|c|c|c|c|}
\hline $\begin{array}{c}\text { Cluster } \\
\text { (Number, Color) }\end{array}$ & $\%$ & Main Keyword & \multicolumn{2}{|c|}{ Top 10 Associated Keywords } \\
\hline 1, pink & $52 \%$ & Art & $\begin{array}{l}\text { Visual Art } \\
\text { Photography } \\
\text { Iconography } \\
\text { Ekphrasis } \\
\text { Aesthetics }\end{array}$ & $\begin{array}{c}\text { Image } \\
\text { Perception } \\
\text { Poetry } \\
\text { Memory } \\
\text { Art Education }\end{array}$ \\
\hline 2 , green & $20 \%$ & Visual Culture & $\begin{array}{c}\text { Painting } \\
\text { Contemporary Art } \\
\text { Art History } \\
\text { Street Art } \\
\text { Graffiti }\end{array}$ & $\begin{array}{c}\text { Identity } \\
\text { Visual Perception } \\
\text { Conservation } \\
\text { Gender } \\
\text { Landscape }\end{array}$ \\
\hline
\end{tabular}


Table 1. Cont.

\begin{tabular}{|c|c|c|c|c|}
\hline $\begin{array}{c}\text { Cluster } \\
\text { (Number, Color) }\end{array}$ & $\%$ & Main Keyword & \multicolumn{2}{|c|}{ Top 10 Associated Keywords } \\
\hline 3 , red & $13 \%$ & Modernity & $\begin{array}{c}\text { Architecture } \\
\text { Culture } \\
\text { Embroidery } \\
\text { Material Culture } \\
\text { Exhibition }\end{array}$ & $\begin{array}{c}\text { Heritage } \\
\text { Embodiment } \\
\text { Graphic Design } \\
\text { Museum Education } \\
\text { Orientalism }\end{array}$ \\
\hline 4 , yellow & $8 \%$ & Music & $\begin{array}{c}\text { Physiology } \\
\text { Synesthesia } \\
\text { Publication } \\
\text { Visual Music } \\
\text { Abstract Animation }\end{array}$ & $\begin{array}{c}\text { Altarpieces } \\
\text { Experimental Film } \\
\text { Materiality } \\
\text { Motion } \\
\text { Performing Arts }\end{array}$ \\
\hline 5 , purple & $7 \%$ & History & $\begin{array}{l}\text { Education } \\
\text { Film } \\
\text { Cinema } \\
\text { Imagination } \\
\text { Astronomy }\end{array}$ & $\begin{array}{c}\text { Ethnology } \\
\text { Science } \\
\text { Symbolism } \\
\text { Anatomy } \\
\text { Books, Illustrated }\end{array}$ \\
\hline
\end{tabular}

Main keyword: Term with the highest number of occurrences, which gives the cluster its name.

The list of 4897 keywords originated from the co-occurrence matrix, where it was observed that cluster 1 (pink color) is the one that shows the highest centrality and density, being the central subject of study and having the highest degree of development. Cluster 2 (green color) represents the topics of research, development, and specialization. Cluster 3 (red color) has a lower density and a relative centrality. These are related to important themes within the field, and capable of becoming central and developed themes. Clusters 4 and 5 (in yellow and purple colors, respectively) contain keywords with low density and centrality, therefore, these groups analyze peripheral themes, such as symbolism or performing arts. Next, the content of each of the five lines of investigation detected on visual art during the period 1952-2020 was characterized and described as follows.

- Cluster 1 (Art): This line of research examines the link of the concept "art", understood as any activity or object carried out with an aesthetic and communicative purpose, to express ideas, emotions, and a particular vision of the world. In this theme, art has been strongly associated with "visual art" to defy expectations, in addition to creative and cultural limits $[7,48]$. Likewise, the research develops the concept of ekphrasis, referring to the verbal representation of a visual representation, real or fictitious, and inserted in a narrative. Along the same line, the relationship between the notion of aesthetics and art has been studied, establishing borders with beauty, creativity, and sensitivity, through historical and geographical variables, to define the society of the image and diffuse aestheticization [49,50]. The scientific production of this school of knowledge has also overseen relating art with feminism, language, pedagogy, subjectivity, politics, propaganda, psychoanalysis, religion, typography, anthropology, calligraphy, digital art, graphic novel, or iconology. The act of creativity develops the imagination, which favors having an open mind and facilitating the understanding of different realities. In this sense, learning to understand the qualities of the environment helps university students to train and produce unlimited creative solutions [51,52]. The associated countries/territories are China, Japan, and Modena (Italy).

- Cluster 2 (Visual Culture): This thematic line developed the term "visual culture" referring to visual realities, especially artificial ones, that express and shape the way of thinking and feeling of man. This term was coined in the 18th century, where aesthetics and the history of art were born, to interpret the artificial images that emerged from the Antiquity $[7,53]$. The connotations, realities, and meanings of visual culture throughout history have set the trends for the transmission of messages and have 
motivated man to express and model different ways of thinking, living, and loving. An example is the case of the most famous French cartoonist, Honore Daumier, imprisoned for lampooning the King in 1831 [54]. This line of research is associated with painting, contemporary art, street art, graffiti, identity, visual perception, conservation, landscape, portrait, art therapy, conceptual art, cultural identity, creative process, humor, decoration, or energy conservation, among other terms. Visual culture is related to visual literacy and ICT. The creation of educational, dynamic, and interactive spaces that result in new cognitive and emotional experiences are relevant to today's society: globalized and image centered, these are the key to higher education $[27,55]$. Likewise, the main associated regions are Catalonia (Spain), Florence (Italy), Naples (Italy), Germany, India, and Singapore.

- Cluster 3 (Modernity): The third school of knowledge is led by the term "modernity" referring to social and historical processes originating in Europe since the Renaissance. Its continuous analysis suggests that it is anchored to a new type of society that arose from the great transformations that occurred in Europe and North America, and that culminated in the industrial and democratic revolutions, which began in the late 18th and early 19th centuries [56,57]. The changes produced in the history of art throughout history have been linked to the change of knowledge in society and philosophical and scientific theories. The changes produced in the history of art over time have been linked to various events related to the evolution of society, philosophical theories, and scientific advances. This has generated on many occasions the idea that, to enjoy art, one must have a certain aesthetic sensitivity and the previous knowledge of the artist's creative process [18]. This component is associated with architecture, culture, embroidery, heritage, graphic design, realism, museum, television, avant-garde art, criticism, historiography, nationalism, tapestry, theology, or transculturation, among other terms. The regions linked to the development of this line of research are New York (United States), Nigeria, Paris (France), and Sweden.

- Cluster 4 (Music): This school of knowledge is directed by the term "music". The English critic Roger Fry in 1912 developed the concept of visual music by linking both elements, and making reference to the work of the Russian artist Wassily Kandinsky, whose paintings merge the perception of hearing and sight [58]. This research describes how sound is a symptom of movement and that sound can also be seen with the eye. In this sense, visual music participates in both art and technology, where its representatives have been obsessed with seeing sound or listening to images, from Victorian science rooms to digitally animated staging [7]. This line of research is associated with physiology, synesthesia, visual music, abstract animation, altarpieces, experimental film, performing art, abstract art, abstract film, cosmopolitanism, or electromyography, among other terms. The drawn or graphic sound constitutes a field that is in continuous expansion and a starting point to represent and experience emotions or feelings that university students pass through in a visual way [17]. The countries linked to this line of knowledge are Finland and South Africa.

- Cluster 5 (History): This fifth line of research is led by the term "history" and its association with visual art. At a global level, research developed the study of visual culture and artistic processes in modern societies, from the invention of the printing press, enabling the dissemination of images, to globalized concepts of visual culture, with new technologies and the digital humanities $[15,56,59,60]$. It is a school of knowledge with an interdisciplinary approach that relates the history of art with visual studies, including the renewal of artistic perspectives and approaches, graphics, documentaries, and other tools to involve and approach the collective imagination [61]. This thematic line is linked with education, imagination, astronomy, ethnology, science, symbolism, anatomy, migration, anamorphosis, exile, precarity, or psychiatry, among other terms. This line of knowledge is primarily associated with Europe.

Figure 3 shows the five clusters in which the keywords and their links were grouped, identifying each group with a color. The analysis of the keywords made it possible to 
provide a label to each group, thus representing the term with the highest weight within each cluster obtained.

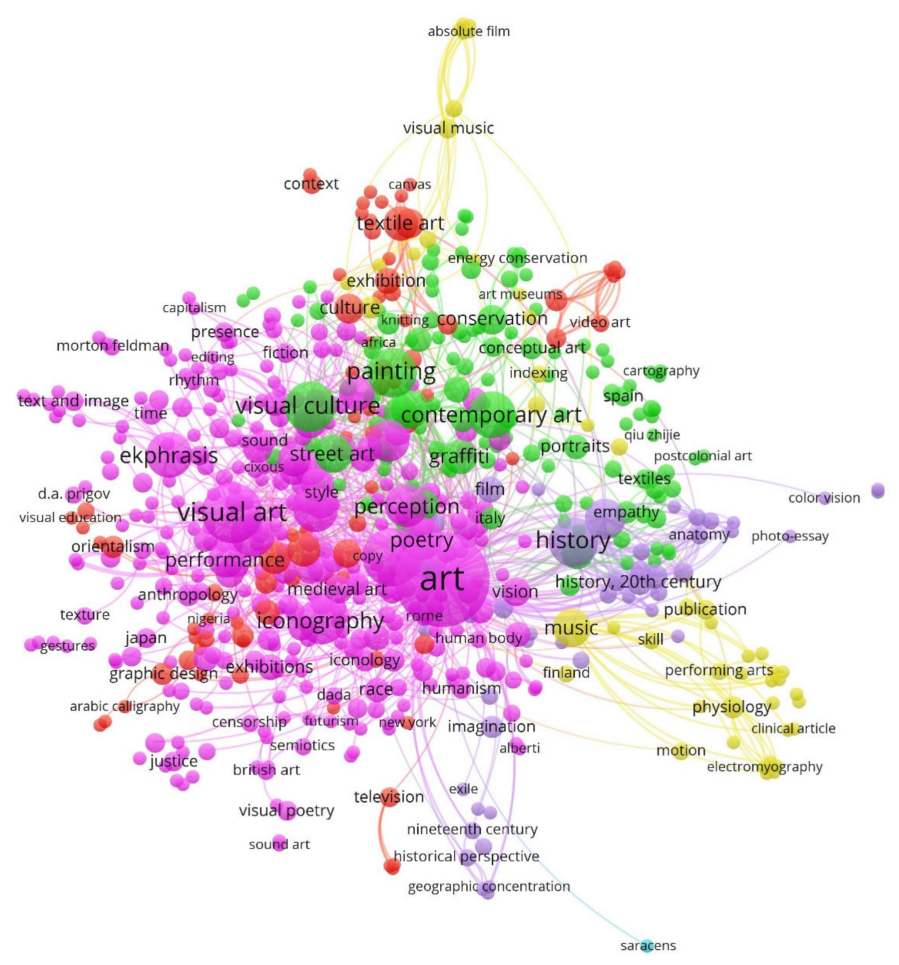

Figure 3. Map of keywords based on co-occurrence method (1952-2020).

\subsection{Evolution of Keywords: Future Directions of Research}

Figure 4 shows the five clusters in which the keywords and their links were grouped, identifying each group with a color. Keyword analysis applying co-occurrence detection allowed for the articles to be grouped into function groups of the keywords used.
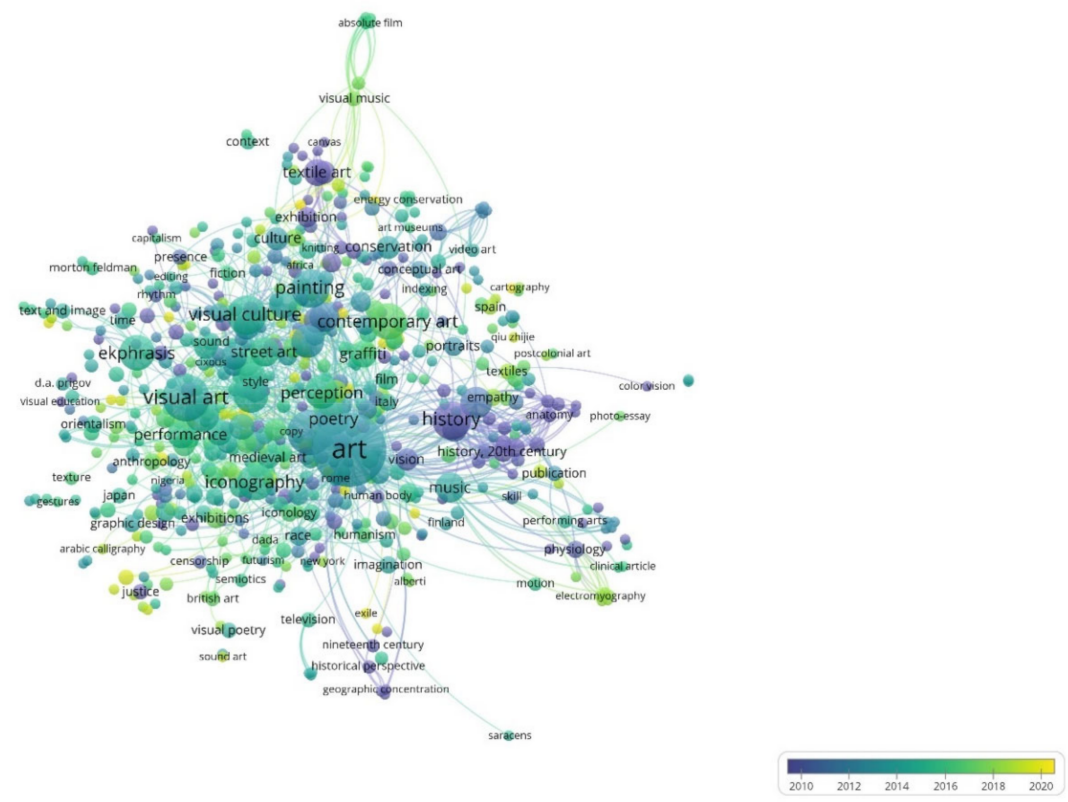

Figure 4. Evolution of keywords based on co-occurrence method (1952-2020).

The group of pioneering keywords (blue-violet color) allowed us to form the basis of the study. This group includes keywords such as: color vision, textile art, conceptual art, 
exhibition, vision, or conservation. These early contributions developed the basic concepts that would support the visual arts research field at the university level [2,62]. In a central group (teal color), the most relevant terms of the investigation were incorporated, such as contemporary art, performance, visual art, art, visual education, performing arts, image, conservation, or art museum [63,64].

Subsequently, the last terms (yellow-green color) that were incorporated into the research of the visual arts were abstract art, abstract painting, antiquarian, frescoes, iconicity, image statistics, reconstruction, renaissance, and sound art $[65,66]$, or the analysis of the work of the Chinese artist Qiu Zhijie, who deals with the struggle between the forces of destiny, self-assertion, social fragmentation, or transience [67]. In relation to the latest terms incorporated into the research, these can be considered as emerging research lines.

Future lines of research related to the visual arts in educational ecosystems should be aimed at developing student skills both to work collaboratively and to learn to adapt to changing environments. For this reason, the process of knowledge and skills transfer must be transformed, so that the research leads us to observe the need to adapt the educational ecosystem so that societies progressively improve [68-70].

\section{Conclusions}

The objective of this study was to analyze the evolution of scientific production and research trends at an international level on the visual arts in the university educational ecosystem, from 1952 to 2020. Bibliometric techniques were applied to a sample of 1727 articles selected from the Scopus database. The evolution of the number of articles in the thematic area of the "Arts and Humanities" was identified. Globally, the general trend in research has followed an upward trend with adequate publication rates over the last decade, making up practically $70 \%$ of scientific production. The significant growth in research activity has led to an advance in the development of guidelines to improve the quality of arts education at all levels. This is related to the new challenges of society that require examining complementary paths for education. In this sense, in 2006, UNESCO proposed an action plan that considers the contribution of artistic education to satisfy the creativity and cultural awareness needs of the 21st century.

Likewise, the five main schools of knowledge developed in this period were detected, which focused on different aspects and approaches of the visual arts such as: (i) art, (ii) visual culture, (iii) modernity, (iv) music, and (v) history. On the other hand, future research directions should focus primarily on abstract art, abstract painting, antiquarian, frescoes, iconicity, image statistics, reconstruction, renaissance, and sound art. These related emerging research lines should be aimed at developing the collaborative work skills of students to learn how to adapt to changing environments. In this way, the emerging research can analyze the adaptation of the educational ecosystem to the process of transferring knowledge and skills to obtain societies that adapt, mutate, and progress.

For these reasons, the main contribution of this study was to analyze the schools of thought, that is, the current and future lines of research carried out during the period analyzed, from the point of view of the visual arts in educational ecosystems. Educational ecosystems should be aimed at developing the student's skills to work collaboratively and learn to adapt to rapidly changing environments. The knowledge and skills transfer process must be transformed. For this reason, the research leads us to observe the need to adapt the educational ecosystem so that societies can further prosper.

Research in the field of visual arts of the university educational ecosystem has an upward trend, indicating an upward interest in the academic and scientific community. This research also contributes to generating new qualitative knowledge, as well as an entry point for future discussions. It is necessary to recognize that an important source of uncertainty in this work is that the data and results originate from the previous literature, and thus are a series of assumptions based on the precision and fidelity of these documents. Furthermore, the findings of this study can provide supporting data for the development 
of future research on visual arts in the university educational ecosystem, and for decisionmaking at research institutions related to educational projects.

Author Contributions: Conceptualization, methodology, software, validation, formal analysis, investigation, data curation, writing —original draft preparation, writing — review and editing, visualization, supervision, E.A.-S. and M.-D.G.-Z.; project administration, M.-D.G.-Z.; resources, E.A.-S. All authors have read and agreed to the published version of the manuscript.

Funding: This research received no external funding.

Institutional Review Board Statement: Not applicable.

Informed Consent Statement: Not applicable.

Data Availability Statement: The data were obtained from Elsevier's Scopus database (https:// www.scopus.com/) accessed on 5 March 2021.

Conflicts of Interest: The authors declare no conflict of interest.

\section{References}

1. Williams, R. Enacting wide-awakeness: Stories of challenging moments and personal change in high school visual arts. Vis. Arts Res. 2020, 46, 28. [CrossRef]

2. Arbuz-Spatari, O. Art-Subject-Object in artistic and plastic creativity of pupils and students in artistic education. Rev. Artist. Educ. 2019, 18, 233-240. [CrossRef]

3. Davis-Cotton, D. Arts integration: A survey of attendance at school and community arts events in florida. Arts Educ. Policy Rev. 2020, 1-13. [CrossRef]

4. Manzella, D. Photography and art education. Art Educ. 1957, 10, 15. [CrossRef]

5. Thieleking, R.; Medawar, E.; Disch, L.; Witte, A.V. Art.pics database: An open access database for art stimuli for experimental research. Front. Psychol. 2020, 11. [CrossRef]

6. Crawshaw, J. Artist-led building: Farming organic knowing. J. Vis. Art Pract. 2020, 19, 1-18. [CrossRef]

7. Douglas, A.; Coessens, K. Experiential knowledge and improvisation: Variations on movement, motion, emotion. Art Des. Commun. High. Educ. 2012, 10, 179-198. [CrossRef]

8. Golomb, C. Artistic development. In The Curated Reference Collection in Neuroscience and Biobehavioral Psychology; Elsevier Science Ltd.: Amsterdam, The Netherlands, 2016; pp. 74-88. ISBN 9780128093245.

9. Sankowski, E. Emotion and the appreciation of art. J. Aesthetic Educ. 1976, 10, 45. [CrossRef]

10. Rusanen, S.; Malinen, P.; Rintakorpi, K. Art, agency and environment-the perspectives of youth culture and the culture of children. Procedia-Soc. Behav. Sci. 2012, 45, 407-415. [CrossRef]

11. Hollanek, T. AI transparency: A matter of reconciling design with critique. AI Soc. 2020, 1-9. [CrossRef]

12. París, A.C.; Sotés-Elizalde, M.Á. Opera and aesthetic formation: A proposal from an artistic education perspective. Procedia-Soc. Behav. Sci. 2010, 2, 2819-2823. [CrossRef]

13. Muth, C.; Briesen, J.; Carbon, C.C. "I like how it looks but it is not beautiful": Sensory appeal beyond beauty. Poetics 2020, 79 . [CrossRef]

14. Toxirovna, A.N. Colors and their artistic image creation features. Int. J. Integr. Educ. 2020, 3, 251-254. [CrossRef]

15. Liu, X. Artistic reflection on artificial intelligence digital painting. J. Phys. Conf. Ser. 2020, 1648, 032125. [CrossRef]

16. Bukharova, E.; Urozhenko, O. Artistic reality in the space of digital technologies: Towards the problem of art criticism. Quest. Expertise Cult. Arts Des. 2020, 9-14. [CrossRef]

17. Hall, A. Drawing as a democratic space within higher education, fine and applied arts: Categorization, process, outcome. Draw. Res. Theory Pract. 2019, 4, 201-223. [CrossRef]

18. Barwell, I. How does art express emotion? J. Aesthet. Art Crit. 1986, 45, 175. [CrossRef]

19. Joy, S.P. Innovation motivation and artistic creativity. J. Creat. Behav. 2005, 39, 35-56. [CrossRef]

20. Al-Bayati, N.K.K.; Al-Bayati, N.A.A. Using the digital techniques as an enrichment media to the formational unit in the artistic design for the walling. Int. J. Psychosoc. Rehabil. 2020, 24, 1178-1191. [CrossRef]

21. Shaw-Miller, L. Building touched with emotion. Art Hist. 2020, 43, 1066-1069. [CrossRef]

22. Levy, E. Art critics and art publics: A study in the sociology and politics of taste. Empir. Stud. Arts 1988, 6, 127-148. [CrossRef]

23. Chatterjee, A.; Widick, P.; Sternschein, R.; Smith, W.B.; Bromberger, B. The assessment of art attributes. Empir. Stud. Arts 2010, 28, 207-222. [CrossRef]

24. Schlegel, A.; Alexander, P.; Fogelson, S.V.; Li, X.; Lu, Z.; Kohler, P.J.; Riley, E.; Tse, P.U.; Meng, M. The artist emerges: Visual art learning alters neural structure and function. NeuroImage 2015, 105, 440-451. [CrossRef]

25. Hsiao, C.-Y. Enhancing children's artistic and creative thinking and drawing performance through appreciating picture books. Int. J. Art Des. Educ. 2010, 29, 143-152. [CrossRef]

26. Riley, H. Visual art and social structure: The social semiotics of relational art. Vis. Commun. 2013, 12, 207-216. [CrossRef] 
27. González-Zamar, M.-D.; Abad-Segura, E.; de la Rosa, A.L.; López-Meneses, E. Digital education and artistic-visual learning in flexible university environments: Research analysis. Educ. Sci. 2020, 10, 294. [CrossRef]

28. Mustaqim, K. Drawing perform's: An artistic research. Int. J. Creat. Arts Stud. 2018, 5, 55-66. [CrossRef]

29. Maximova, M. Commercial art galleries as canon-makers: The moscow art scene in the early 1990s. J. Vis. Art Pract. 2020, 19, 269-283. [CrossRef]

30. Cosumov, M. Artistic education/education through art in contemporary school from a transdisciplinary perspective. Rev. Artist. Educ. 2019, 18, 324-329. [CrossRef]

31. Islam, M.A.; Agarwal, N.K. What is the impact of library and information science on knowledge management research? Vine J. Inf. Knowl. Manag. Syst. 2020, 51, 1-26. [CrossRef]

32. Aydin Rzayeva, G. Information creativity as a right in the new society. Vilnius Univ. Open Ser. 2020, 180-191. [CrossRef]

33. Broeckmeyer, M. Impulsive incantations-voicing migraine. J. Artist. Res. 2020. [CrossRef]

34. Cronin, B. Bibliometrics and beyond: Some thoughts on web-based citation analysis. J. Inf. Sci. 2004, 27, 1-7. [CrossRef]

35. Adriaanse, L.S.; Rensleigh, C. Web of science, scopus and google scholar a content comprehensiveness comparison. Electron. Libr. 2013, 31, 727-744. [CrossRef]

36. Aghaei Chadegani, A.; Salehi, H.; Md Yunus, M.M.; Farhadi, H.; Fooladi, M.; Farhadi, M.; Ale Ebrahim, N. A comparison between two main academic literature collections: Web of science and scopus databases. Asian Soc. Sci. 2013, 9, 18-26. [CrossRef]

37. González-Zamar, M.-D.; Abad-Segura, E.; López-Meneses, E.; Gómez-Galán, J. Managing ICT for sustainable education: Research analysis in the context of higher education. Sustainability 2020, 12, 8254. [CrossRef]

38. Stewart, L.A.; Clarke, M.; Rovers, M.; Riley, R.D.; Simmonds, M.; Stewart, G.; Tierney, J.F. Preferred reporting items for a systematic review and meta-analysis of individual participant data. JAMA J. Am. Med Assoc. 2015, 313, 1657-1665. [CrossRef]

39. Abad-Segura, E.; González-Zamar, M.-D. Sustainable economic development in higher education institutions: A global analysis within the sdgs framework. J. Clean. Prod. 2021, 294, 126133. [CrossRef]

40. Wei, W.; Guo, C. A text semantic topic discovery method based on the conditional co-occurrence degree. Neurocomputing 2019, 368, 11-24. [CrossRef]

41. González-Zamar, M.-D.D.; Abad-Segura, E. Implications of virtual reality in arts education: Research analysis in the context of higher education. Educ. Sci. 2020, 10, 225. [CrossRef]

42. Van Eck, N.J.; Waltman, L. Visualizing bibliometric networks. In Measuring Scholarly Impact; Springer International Publishing: New York, NY, USA, 2014; pp. 285-320.

43. Van Eck, N.J.; Waltman, L. Software survey: VOSviewer, a computer program for bibliometric mapping. Scientometrics 2010, 84, 523-538. [CrossRef] [PubMed]

44. Waltman, L.; Van Eck, N.J. A new methodology for constructing a publication-level classification system of science. J. Am. Soc. Inf. Sci. Technol. 2012, 63, 2378-2392. [CrossRef]

45. Michael, M.K. Repositioning artistic practices: A sociomaterial view. Stud. Contin. Educ. 2019, 41, 277-292. [CrossRef]

46. Butler, J.F. The visual arts in the younger churches. Int. Rev. Mission 1952, 41, 374-390. [CrossRef]

47. Contreras-Medina, F.R. Estudio sobre los planteamientos teóricos y metodológicos de los estudios visuales (study on the theoretical and methodological approaches of visual studies). ArteIndividuo Y Soc. 2017, 29, 483-499. [CrossRef]

48. Ross, J.H.S. Drawing: From education to artistic practice. Vis. Inq. 2013, 2, 71-75. [CrossRef]

49. Barr, P. Film adaptation as experimental game design. Arts 2020, 9, 103. [CrossRef]

50. Erkan, İ. Investigation of the contribution of virtual reality to architectural education. Art Des. Commun. High. Educ. 2020, 19, 221-240. [CrossRef]

51. Demirel, I.N. Contributions provided by visual arts lesson for students at secondary stage in elementary education. Procedia-Soc. Behav. Sci. 2011, 15, 1972-1976. [CrossRef]

52. Lemonchois, M. Artistic practical activities in art education. Palíndromo 2021, 13, 75-89. [CrossRef]

53. Boguszewska, A. About visual education in the context of artistic illustration: Historical and contemporary aspect. Probl. Opiekuńczo-Wychowawcze 2020, 587, 14-23. [CrossRef]

54. Hofmann, W. Ambiguity in daumier (\& elsewhere). Art J. 1983, 43, 361-364. [CrossRef]

55. Toister, Y. Latent digital. J. Vis. Art Pract. 2020, 19, 125-136. [CrossRef]

56. Paşca, E.M. History and modernity in artistic education from romania. Rev. Artist. Educ. 2019, 18, 347-352. [CrossRef]

57. Ball, N. The graphic design process: How to be successful in design school, anitra nottingham and jeremy stout (2019). Art Des. Commun. High. Educ. 2020, 19, 119-121. [CrossRef]

58. Steger, S.; Oesterle, D.; Bretz, S.; Frenzel, L.; Stege, H.; Winkelmeyer, I.; Hahn, O.; Geiger, G. Kandinsky's fragile Art: A multidisciplinary investigation of four early reverse glass paintings (1911-1914) by wassily kandinsky. Herit. Sci. $2019,7$. [CrossRef]

59. Frank-Witt, P. Intentionality in art: Empirical exposure. J. Vis. Art Pract. 2020, 19, 297-309. [CrossRef]

60. Caldwell, H.; Whewell, E.; Heaton, R. The impact of visual posts on creative thinking and knowledge building in an online community of educators. Think. Ski. Creat. 2020, 36. [CrossRef]

61. Richard, V.; Aubertin, P.; Yang, Y.Y.; Kriellaars, D. Factor structure of play creativity: A new instrument to assess movement creativity. Creat. Res. J. 2020, 32, 383-393. [CrossRef] 
62. Pfeiler-Wunder, A.; Sutters, J.; Buffington, M.; Rao, S.; Rice, L. Understanding the relationship between research and practice: A national survey of visual art educators. Vis. Arts Res. 2020, 46, 85. [CrossRef]

63. De Araújo, T.N. Museum to open skies: Tombstone art and education. Procedia Soc. Behav. Sci. 2014, 116, 3705-3708. [CrossRef]

64. McAvoy, M. Theater arts, global education, and policy; or, what chance the rapper taught us about arts education. Arts Educ. Policy Rev. 2020, 121, 98-105. [CrossRef]

65. Foá, M. Narrative traces through being and places, drawing, performance drawing and painting. Draw. Res. Theory Pract. 2020, 5, 85-98. [CrossRef]

66. González-Zamar, M.-D.; Abad-Segura, E. Digital design in artistic education: An overview of research in the university setting. Educ. Sci. 2021, 11, 144. [CrossRef]

67. Hopfener, B. Qiu zhijie as historian: Media critique as a mode of critical historical research. World Art 2015, 5, 39-61. [CrossRef]

68. Edgar, S.N.; Morrison, B. A vision for social emotional learning and arts education policy. Arts Educ. Policy Rev. 2020, 1-6. [CrossRef]

69. Gale, C. Art School as a transformative locus for risk in an age of uncertainty. Art Des. Commun. High. Educ. 2020, 19, 107-118. [CrossRef]

70. Pautz, M.C.; Vogel, M.D. Investigating faculty motivation and its connection to faculty work-life balance: Engaging public service motivation to explore faculty motivation. J. Public Aff. Educ. 2020, 26, 437-457. [CrossRef] 